\title{
The Importance of Cancer Cell Lines as in vitro Models in Cancer Methylome Analysis and Anticancer Drugs Testing
}

\author{
Daniela Ferreira, Filomena Adega and Raquel Chaves
}

Additional information is available at the end of the chapter

http://dx.doi.org/10.5772/53110

\section{Introduction}

Cancer is a molecularly heterogeneous disease [1] and one of the major causes of death worldwide. The existence of various types of tumours with different histopathologies, genetic and epigenetic variations, and clinical outcomes [2], difficult the understanding of this disease, the mechanisms of action of chemotherapeutics and the creation of novel therapies.

The advances in the cancer pathobiology study has its origin on the availability of different types of experimental model systems that review the various forms of this disease [2], allowing the knowledge of genetics and epigenetics alterations and anticancer drugs testing. Studies of cancer rely on the use of primary tumours [1, 3], paraffin-embedded samples [1], cancer cell lines $[1,3,4]$, xenografts $[2,5,6]$, tumour primary cell cultures $[3,4]$ and/or genetically engineered mice [2]. Each of these diverse models are used for different studies, mainly because certain types of manipulations for the genetic and DNA methylation analysis and drug testing are ethically, and in practice, difficult to perform in animals. Cell lines emerge as a feasible alternative to overcome these issues, being at the same time easy to manipulate [3] and molecularly characterize (e.g. genetic and/or epigenetically). This cell model is exceptional for the fundamental study of the cellular pathways and for disclosing critical genes involved in cancer. Nevertheless, a detailed characterization is fundamental before its use. This characterization provides important insights about the complexity of the polygenetic etiology of cancer and the biological mechanisms involved in this disease [1] reinforcing its value as models for its study [1,7]. Also the characterization of cancer cell lines is essential for the development of new anticancer drugs, understanding the action mechanisms and the resistance/sensitivity patterns of chemotherapeutics already in use in cancer treatment and the development of more targeted anticancer drugs. 


\section{Cancer cell lines as a model for cancer study}

Cancer cell lines have been widely used for research purposes and proved to be a useful tool in the genetic approach, and its characterization shows that they are, in fact, an excellent model for the study of the biological mechanisms involved in cancer [1]. Examples are shown in table 1 . The use of cancer cell lines allowed an increment of the information about the deregulated genes and signalling pathways in this disease [2, 8]. Furthermore, the use of the cell model was in the origin of the development and testing of anticancer drugs presently used [8-10], and in the development of new therapies [1, 10, 11], but also as an alternative to transplantable animal tumours in chemotherapeutics testing [12]. In fact, the use of the appropriate in vitro model in cancer research is crucial for the investigation of genetic, epigenetic and cellular pathways [1], for the study of proliferation deregulation, apoptosis and cancer progression [2], to define potential molecular markers [3] and for the screening and characterization of cancer therapeutics [10,13]. The results of the research in cancer cell lines are usually extrapolated to in vivo human tumours [3] and its importance as models for drug testing and translational study have been recognized by many biomedical and pharmaceutical companies [8].

\begin{tabular}{cccc} 
Cancer cell line & Species & & Morphology \\
\hline HeLa & Homo sapiens & Cervix adenocarcinoma & Epithelial \\
MCF-7 & Homo sapiens & Breast adenocarcinoma & Epithelial \\
U87MG & Homo sapiens & Glioblastoma-astrocytoma & Epithelial \\
\hline HT-29 & Homo sapiens & Colon adenocarcinoma & Epithelial \\
A549 & Homo sapiens & Lung carcinoma & Epithelial \\
\hline HEP-G2 & Homo sapiens & Hepatocellular carcinoma & Epithelial \\
K-562 & Homo sapiens & Chronic myeloid leukaemia & Lymphoblast \\
Cos7 & Cercopithecus aethiops & SV40 transformed - kidney & Fibroblast \\
\hline PC3 & Homo sapiens & Prostate adenocarcinoma & Epithelial \\
A375 & Homo sapiens & Malignant melanoma & Epithelial \\
\hline
\end{tabular}

Table 1. Examples of some widely used cancer cell lines with origin in different cell types. These data were obtained from the European Collection of Cell Cultures (ECCC) and American Type Culture Collection (ATCC).

In spite of the essential role of cancer cell lines in biomedical research, there is a debate among the scientific community on the fact whether they are or not representative of the original tumour $[5,14]$. Some authors agree with the idea that there is a high, but not perfect, genomic similarity between the original tumour and the cancer cell line derived from it [8, 13, 15-17]. Cancer cell lines maintain the tumour-specific chromosome abnormalities in the first passages [15], show the same morphologic and molecular characteristics of the primary tumour [16] and, in general, maintain the expression of the "hallmarks of cancer", with exception of angiogenesis that requires the presence of stromal 
tissues [8]. As an example, Tomlinson and colleagues (1998) compared a breast primary tumour and a cell line originated from that tumour. These authors reported the same BRCA1 mutation and an identical pattern of allelic loss in multiple loci, indicating that the cell line preserves numerous characteristics of the original tumour [17]. Also the data from Finlay and Bagulay (1984) demonstrated that the cancer cell lines have a similar response to anticancer drugs when compared to the original tumour [18].

The fact that a large number of long-established cancer cell lines were originated from aggressive and metastatic tumours [4,5], restrict the study of cancer progression and of drug therapies development. Cancer cell lines derived from earlier stage and lower grade disease seems to be the more promising models. In comparative studies made between cancer cell lines derived from earlier stage tumours and the original tumour tissues showed good concordance in several parameters, including the state of P53 (100\%) and ERBB2 (93\%) [4]. This shows that this type of cells are more representative of the original tumour [4], reflecting more accurately the events that occur in cancer cells in vivo [5].

While cancer cell lines retain many genetic, epigenetic and gene expression features [3], they are genetically more complex than the tumour itself [13]. The differences between cancer cell lines and the respective tumours may be explained by the prior selection of initial cells and the in vitro Darwinian evolution [3]. Cancer cell lines typically present extensive chromosomal rearrangements, oncogene mutations, allelic loss and gene amplifications. This can lead to a loss of phenotypic properties and additional molecular changes during the cell culturing for long times [14], including modifications in some cellular pathways [3].

There are numerous reasons for the use of cancer cell lines as an experimental model for the study of cancer [2]. They have many intrinsic advantages for cancer research and for new therapeutic approaches, increasing their value [8]. Some of the advantages (table 2) of this model are listed below:

- Easiness to handle and manipulate [2-4]. This is an important and, in some cases an exclusive characteristic of this model [8]. Cell lines can be genetically/epigenetically manipulated using demethylation agents [1, 19], siRNA [20], expression vectors [10] and pharmacologically manipulated using cytostatics [13].

- High homogeneity [2-4]. The heterogeneity of solid tumours difficult their analysis and cancer cell lines allow the analysis of a homogeneous population of tumour cells [21]. This homogeneity can be seen as a disadvantage because of the natural heterogeneity of the tumour. However, this can be overcome using a panel of cancer cell lines representative of the heterogeneity observed in the primary tumours [2].

- High degree of similarity with the initial tumour [17]. Cancer cell lines are pure populations of tumour cells and they represent these cells without the complexity of the in vivo environment (stromal and inflammatory cells). This can be seen also as a disadvantage [8].

- Large number and variety of cancer cell lines available [8], although poorly characterized [5].

- Immediate accessibility to the scientific community [1, 8]. 
- Unlimited auto-replicative source, in continuous cell lines [4].

- $\quad$ Easy substitution of contaminated cultures for the respective frozen cell lines [4].

- Reproducibility of results in the correct conditions [3].

Nevertheless, some disadvantages or limitations (table 2) must be taken into account:

- Some cell lines may have cross contamination with HeLa cells. A large number of cancer cell lines in the cell banks (the most used) have been reported as contaminated with HeLa cells $[3,4,8]$.

- Genomic instability [3,4] which may cause differences between the original tumour and the respective cell line [3]. The genotypic and phenotypic drift is more common in continuous cultures, especially the ones deposited in cell banks for many years. The phenotypic changes can occur by the appearance of subpopulations selected from more competitive clones $[3,4]$. This can be partially solved (in more recent cancer cell lines) limiting the number of passages and using frozen cells with few passages [3].

- Culture conditions, that can change the morphology, the gene expression and several cellular pathways [3].

- Infections with mycoplasma that can change the culture properties [3].

- Difficulty in the establishment of long-term cancer cell lines of certain types of tumours [22].

- $\quad$ Cell culture environment is different from that of the original tumour [2].

- $\quad$ Loss of the natural heterogeneity of the tumour [2].

Advantages of the use of cancer cell lines

- $\quad$ Easy to handle and manipulate [2-4].

- High homogeneity [2-4].

- High degree of similarity with the initial tumour [17].

- High variety available [8].

- Immediate accessibility [1, 8].

- Unlimited auto-replicative source [4].

- Easy substitution [4].

- Reproducibility of results [3].
Disadvantages of the use of cancer cell lines

- Cross contamination with HeLa cells [3, $4,8]$.

- $\quad$ Loss of heterogeneity [2].

- Genomic instability $[3,4]$.

- Possibility of modifying the characteristics of the cells [3].

- Infections with mycoplasma [3].

- Difficulty in the establishment of longterm cancer cell lines [22].

- Different environment of the tumour [2].

Table 2. Advantages and disadvantages of the use of cancer cell lines as models in cancer research.

Some of these problems can be solved by the conjugation with other type of models. Primary cell cultures (derived directly from the tumours) are a viable tool as they maintain some of the heterogeneity of the original tumour. However, the tissue environment is lost and some studies cannot be performed in this model, as those that need several passages [3, 4]. Fresh tumour samples obtained by surgery [3] or tumour samples embedded in paraffin [1] can also be used for the study of cancer biology. These models represent the state of the tumour in vivo with its heterogeneity, but only at a specific evolutionary moment of the 
tumour. This sample is limited in amount and the genetic manipulation is almost impossible [3]. The xenografts models (nude mice) are used for testing the tumorigenicity and metastatic ability of cancer cell lines. They constitute a model for drug testing, providing the in vivo microenvironment for human tumour original cells [2, 3]. However, the immunocompromised mice have a limitation per se by the important role of inflammation in cancer [2,3]. Animal models, with spontaneous or induced tumours [3], have the advantage of providing a historical sequence of the tumour and have been used in the pathobiology research of cancer and for testing new therapeutics in vivo. Besides the ethical problem, this model also holds the difficulty in extrapolating the data to the human counterpart [22]. Another animal model is the genetically engineered mice for cancer that may reproduce human in vivo models [3]. This model is important for elucidating the regulatory mechanisms of cancer initiation and progression, however it cannot recapitulate all the aspects of the cancer [2] and also have limitations regarding genetic manipulation.

In fact, all the experimental models for cancer research present advantages and disadvantages and none of them is completely representative of the phenotype of the tumour $[2,3]$. Nevertheless, cancer cell lines are adequate models for the research of this disease. They provide adequate models for the study of the origin of cancers by the presence of initiating cells or cancer stem cells [2,3] and for drug testing in a first approach [2]. Some cancer cell lines can be used for screening RNAi (RNA interference) libraries and other small molecules as a way to study interacting pathways in the initiation and survival of the tumour [2]. The phenotype and genotype evolutionary study, under selective pressure, can be done in cancer cell lines, to understand the cancer progression until metastasis [3]. The use of a panel of various subtypes of cancer cell lines increases the importance of this model in disclosing the signalling pathways involved in therapeutic response [2]. Cancer cell lines are also an excellent tool for the genetic and epigenetic study of cancer, being the genomic and methylomic profiling of each cancer cell line crucial for cancer research and their use in anticancer drug testing.

\subsection{The importance of the molecular characterization of cancer cell lines}

A cancer cell line is more valuable as an in vitro model for cancer research if it is properly molecularly characterized [1,7]. In Figure 1 this aspect is patent as we can observe an increasing of works regarding cell lines characterization which is accompanied by an increasing number of papers published concerning the use of cancer cell lines as models for cancer research. This type of analysis will allow a more detailed study of the genetic/epigenetic events (e.g. disclose critical cancer genes and DNA methylation alterations) and cellular pathways associated with oncogenesis [21], in the understanding of the microevolutionary progression of the tumour [1] (when the molecular profiling is done in different passages [15]) and unveil the molecular patterns associated with resistance/sensitivity to anticancer drugs [10, 15]. Specifically, the tumour transcriptional profiling and the DNA methylation patterns (i.e. that result in gene expression alterations) can be useful as a first approach in the development of new anticancer targeted therapeutics [9]. 


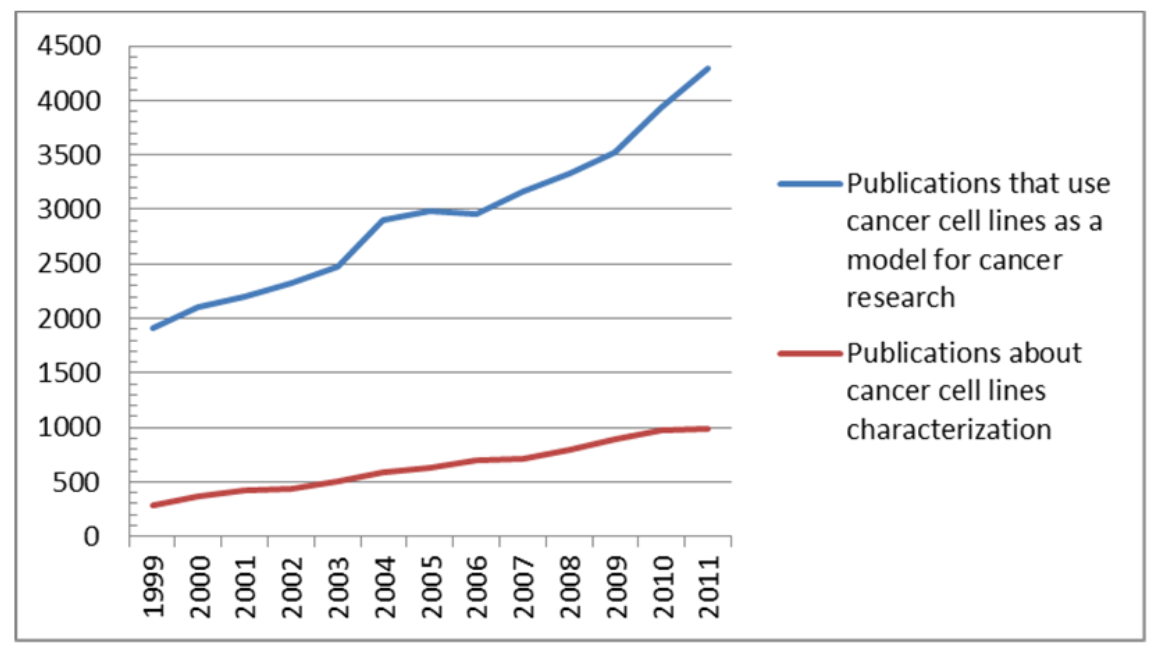

Figure 1. Number of publications regarding: cancer cell lines as models for cancer research (blue line) and cancer cell lines characterization (red line). These data were obtained from the papers indexed in the free resource PubMed (National Center for Biotechnology Information, at the U.S. National Library of Medicine, located at the National Institutes of Health).

The molecular characterization of cell lines molecular characterization can be done at different and complementary platforms - cytogenomic [1, 5, 15], genomic [1, 8], epigenomic $[1,15]$, transcriptomic $[1,13,23]$ and proteomic [24]. In addition, the characterization of the cells morphology [21, 25], the growth rate by the doubling time measurement $[25,26]$, the growth curve [25] and the tumorigenic capacity in athymic nude mice by transplantation of cancer cells to the mice (xenotransplant) [21, 25, 26] should be held. It is also important to characterize cancer cell lines regarding their anchorage independency (soft agarose assay) $[11,26,27]$ that can be significant for studying the interaction of drugs with the cells [28] and at their metastatic migration potential and invasiveness capacity, that can be useful for determining the genes and pathways involved in metastasis [26, 29].

The identification and characterization of chromosomal rearrangements allows the detection of breakpoints and chromosome abnormalities that can be related with deregulation of cancer genes. The characterization of chromosomal instability is also crucial because it can be caused by errors in the DNA damage checkpoints, in the DNA repair pathways and in the mitotic segregation [1].

Also the characterization of DNA amplification is important, as the overexpression of genes can be involved in the oncogenic process, as ERBB2 in some types of breast cancer [1] or other genes that can be druggable targets like kinases [13].

Cell lines molecular profiling that disclose alterations in the cell cycle regulators and other signalling molecules is important $[15,28]$ and can be useful for targeting anticancer drugs for cell cycle defects. The fact that tumour cells with these alterations are more sensitive to anticancer agents highlight the importance of the characterization of cancer cell lines to 
molecules as P53, RB, MDM-2, CDKs, cyclins, apoptotic regulator proteins [28] and the respective genes.

Recently, Louzada and colleagues (2012) performed a genetic and cytogenetic characterization of two rat sister cancer cell lines commercially available, at the levels of morphology, ploidy and identification of clonal chromosome rearrangements and breakpoint regions. They also analysed the expression profile of two oncogenes and the influence of global demethylation in the expression of these genes [1], and realized that these two sister cell lines are a good in vitro cell model for Erbb2.

As referred, the molecular characterization of cancer cell lines is important for anticancer drug testing [16], for the definition of chemosensitivity and resistance pattern [10] and their correlation with candidate cancer genes [10]. As an example, a research from Hakazaki and colleagues (2006) on the characterization of a cancer cell line (FPS-1) derived from an undifferentiated pleomorphic sarcoma (UPS) reported upregulation of the Epidermal growth factor receptor (EGFR) and cyclooxygenase-2 (COX-2) genes, indicating the use of this cell line for the development of drugs that act on these genes or in its cellular pathways [16]. Fang and colleagues (2009), when characterizing cell lines derived from malignant peripheral nerve sheath tumours (MPNST) from patients with metastatic and recurrent disease, identified genes associated with the metastatic potential, indicating some therapeutic approaches targeted for these genes [15]. Finally, a pharmacological and molecular characterization was made in a panel of 60 different types of human cancer cell lines (NCI60) created for the development of anticancer drugs and included DNA, RNA, proteins, chromosome and functional profiling, allowing a better interpretation of the results of anticancer drug tests [30].

The molecular profiling of cancer cell lines also enables an easier assessment of cancer types and subtypes, defining which cell lines are more suitable for the different investigations [13], which in turn, enhances the screening and study of anticancer drugs. Recently, Kao and colleagues (2009) did a characterization of commercially available breast cancer cell lines at the gene expression levels and respective gene copy number variation. They were able to correlate the cancer cell lines with recognized molecular subtypes of breast cancer, concluding which is the most adequate cell line for the study of each tumour subtype [13].

Cancer cell lines must be characterized not only in the first passages, but also during their progression, in different passages [15]. The use of cancer cell lines that were characterized many years ago $[4,31]$ and the contamination of the cell lines deposited in cell banks with HeLa cells are a problem in cancer research $[4,8]$ that requires efforts in their molecular profiling. The problem of the lack of characterization of cancer cell lines that are used for many years [4] was highlighted by Osborne and colleagues (1987) in a study that demonstrated that one of the most used breast cancer cell line (MCF-7) showed different molecular characteristics according to the lab origin [31]. This fact shows the importance of the characterization of these models, that are in cell banks for many years, accumulating, in the meantime, a high number of mutations $[4,8]$. The existence of a large number of cell 
lines deposited in cell banks contaminated with HeLa cells, the first established cancer cell line, is a serious problem $[4,8]$ verified after the appearance of molecular methods as DNA fingerprinting, that showed cross-contaminations in about $18 \%$ of the cell lines deposited in the German Cell Line Bank [4, 8, 32]. The generation of databases with the molecular characterization of cell lines and with the identification of its contaminants [8] is essential for the use of cell lines as credible models. Also the scientific journals, at medium-term, should require the profiling of these lines before the publication of any data $[4,8]$.

\subsection{Methodologies for cancer cell lines molecular profiling}

Several methodologies can be used for a proper molecular characterization of cancer cell lines, therefore, the selection and combination of the appropriate methods is essential.

For the cytogenetic profiling, the study of imbalances or rearrangements at the chromosomal level is initially done using G-banding karyotyping [1, 7, 15, 16, 33]. The identification of breakpoint regions and/or clonal chromosome rearrangements can be further achieved by FISH (Fluorescent in situ Hybridization), usually using chromosome painting and BAC/PAC clones [1]. FISH can also be used for the identification of oncogenes amplification [1,34,35]. Nevertheless, the resolution of such analyses in the detection of DNA gains and losses might be increased using CGH (Comparative Genomic Hybridization) that allows detecting from $10-20 \mathrm{Mb}$ with metaphase chromosomes down to 200 bp with high-density array-CGH using BAC or oligonucleotide arrays [5, 15, 34, 36, 37]. $\mathrm{CGH}$ can be useful in detecting gene imbalances allowing the identification of new important genes that can then be up or downregulated in cancer cell lines [34].

The DNA molecular profiling is possible with the use of DNA fingerprinting [4, 21], RFLP (Restriction Fragment Length Polymorphism), probes chromosome-specific [15, 21], STR (short tandem repeats) profiling [4] or gene sequencing [36]. Techniques such as RT-qPCR (Real-Time Reverse Transcriptase Quantitative PCR) [1, 16, 33, 38, 39], RNA-FISH [1], cDNA microarrays and whole genome DNA microarrays [5, 10, 13, 34, 40] can be used for gene expression profiling of cancer cell lines. RT-qPCR and RNA-FISH (allows single cell analysis) are complementary methods that permit the expression quantification of cancer genes [1]. Whole-genome DNA microarrays techniques are useful for the analysis of the expression profile genome-wide [10, 13] and copy number variations [13] or for the expression analysis of a specific fraction of the genome like promoters, codifying regions, SNPs (Single Nucleotide Polymorphisms), spliced exons or a panel of pre-selected genes related with specific diseases as cancer. For the study of the protein expression level, the most widely used methods are immunohistochemistry $[11,13,15,16,35,38,41]$ and western blotting $[13,16]$.

\subsubsection{Next generation sequencing technologies in cancer cell lines}

Although the referred methodologies have been successfully used in the characterization of cancer cell lines, recently, new promising strategies for analysis of genetic and epigenetic 
alterations have emerged, providing a large amount of information at low cost. These are based in Next Generation Sequencing (NGS), which allows the sequencing of almost all coding regions (and at a low-extension, non-coding sequences) of both the genome and the methylome [42, 43]. The NGS platforms have the power of sequencing massively-parallel short-read DNA [42] with a high-throughput at a low cost [44], substituting some techniques as the Sanger traditional sequencing [45] and microarrays [42]. Incredibly, NGS can produce up to 1 billion of sequences per instrument in four days. However, these results are highly dependent on the analysis with refined bioinformatics programs, and the large amount of information makes the data treatment sometimes difficult $[42,45]$.

NGS is responsible for the recent increase of epigenetic studies, transforming the resolution of the characterization at the epigenetic level $[42,43,46]$, and have allowed the construction of the first map of the human methylome [43]. The genome-wide DNA methylation profiling can be done by array-based or sequencing-based (NGS) with the combination of bisulfite conversion (that transforms the unmethylated cytosines into uracil, preserving the methylated cytosines) or immunoprecipitation of the methylated DNA (MeDIP) [42, 47]. The single-nucleotide resolution of these platforms provides information about the methylation of each cytosine, which is an important mark in oncogenesis. An example of the use of genome-wide DNA methylation immunoprecipitation-sequencing for the methylome profiling in cancer cell lines was made recently by Ruike and colleagues (2010) and their data indicate breast cancer cell lines as being globally hypomethylated and with numerous hypermethylated sequences [48]. For the study of epigenetics genome-wide, a technology that combines chromatin-immunoprecipitation (ChIP) and NGS technologies has been used [42]. The ChIP methodology is based on DNA and proteins interactions and together with NGS platforms (ChIP-Seq) is used to analyse histones' modifications genome-wide, as methylation $[42,43]$.

The development of high-throughput DNA sequencing and whole-genome platforms for the analysis of the transcriptome, methylome, microRNAs and copy number changes is essential for the advance in cancer cell lines profiling. While the use of these platforms for cancer cell lines profiling is only at the beginning, these techniques have already proved its value in the identification of copy number alterations, mutations detection or different methylation patterns of genes [8].

\section{Methylome analysis in cancer}

Besides the genetic alterations (as point mutations, deletions, translocations or amplifications), it is now settled that imbalances in the DNA methylation patterns are key processes in tumour formation and progression [1,49]. Thus, the profiling of cancer cell line models must also be done at the epigenetic level, and more particularly, at the DNA methylation level [5], that leads to heritable alterations of gene expression that do not involve alterations in the sequence of DNA $[5,50,51]$. As can be observed in Figure 2, the methylation analysis in cancer cell lines is still very scarce. 


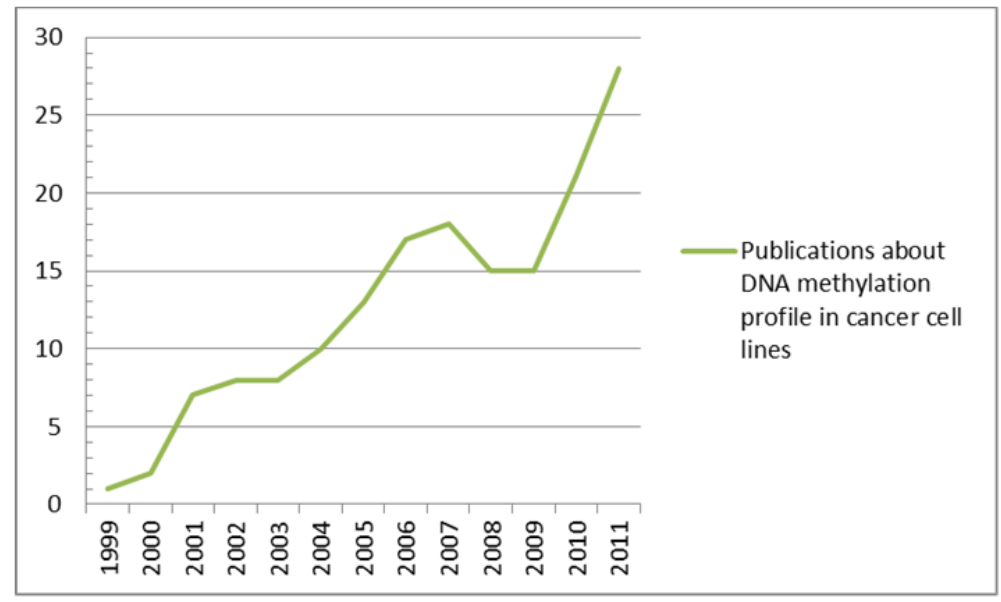

Figure 2. Number of publications regarding cancer cell lines characterization at the DNA methylation level (green line). These data were obtained from the papers indexed in the free resource PubMed (National Center for Biotechnology Information, at the U.S. National Library of Medicine, located at the National Institutes of Health).

The methylation of DNA is a chemical modification catalyzed by DNA methyltransferases (DNMT1, DNMT3A, DNMT3B) [51-53], involving the covalent addiction of a methyl group $\left(\mathrm{CH}_{3}\right)$ to the carbon in the 5-position of the cytosine ring [50-52], normally in a CpG dinucleotide context. $\mathrm{CpG}$ dinucleotide can be grouped in $\mathrm{CpG}$ islands in the promoter region of the genes $[50,53]$.

DNA methylation plays a crucial role in several epigenetic events of normal cells, as genomic imprinting, $X$ chromosome inactivation, retroelement silencing, etc [53], being at the same time important in DNA repair, genomic stability and in the regulation of chromatin structure [50].

Recently, the role of DNA methylation in cancer has been an important subject of research $[47,51,54]$, because we are now aware that the disruption of the methylome is an important hallmark of the oncogenic process [54], both the initiation and progression [47]. Depending on the pattern of the modification, the genome damage can result in the (over)expression or silencing of a gene [51,53], predisposing cells to cancer [51]. The aberrant methylation can begin early in tumorigenesis and can induce most of the pathways modifications in cancer, as loss of cell cycle control and apoptosis signalling, alteration of transcription factors function, disruption of cell-cell or cell-substratum interaction, among others [55]. This deregulation can affect different types of genes as tumour suppressor genes, oncogenes and cancer-associated viral genes [50]. The cancer genome is characterized by a global genomic hypomethylation and a dense hypermethylation of $\mathrm{CpG}$ islands in the regulator regions of genes $[50,51,54]$.

DNA hypermethylation is the most studied epigenetic alteration in cancer [51]. It can be important as a tool for cancer diagnostic, as a biomarker of malignant cells, as a prognostic 
factor [49, 54], and it may represent a good target for future therapy [54]. When aberrant methylation occurs in the promoter region of tumour suppressor genes, it may lead to its silencing [50, 51, 56] and loss of protein function [1]. Thus, the role of aberrant hypermethylation in cancer is easily understood for the transcriptional silencing of important genes in the cancer prevention [49]. The methylation profile is different for different types of tumours, suggesting specificity $[54,56]$. However, it is unknown how this framework acts to "decide" which genes and when are they methylated [51,56]. This profiling can be vital for the premature detection of cancer in sensitive and specific methylation markers and for the identification of important pathways as therapeutic targets [56]. The hypermethylation profiling was already done in different types of tumours, in cancer cell lines (table 3) and in fresh tumours leading to the identification of methylated genes cancer-specific and in different types of cancer [56]. A high concordance was observed between the fresh tumours and the respective cell lines, making them good models for the study of cancer methylome. Hypermethylation can influence the development and preservation of a cell-specific phenotype for the specific silencing of gene sets [5]. The genes that are most susceptible to hypermethylation include genes involved in all the cellular pathways [54]: in cell cycle regulation (P16INK4a [51, 52, 54, 56], P15INK4a [51, 53], PRB [51, 52], P14ARF [51, 54]), in DNA repair (MLH1 [53, 54] BRCA1 [47, 51, 54, 56], MGMT [51, 52, $54])$, in apoptosis (APAF-1 [53, 54], DAPK [51, 54]), and in differentiation, angiogenesis, metastasis and drug resistance [51]. For instance, the hypermethylation can affect the P16INK4 $\alpha / \mathrm{PRB} / \mathrm{CDK} 4$ pathway by the hypermethylation of P16INK4a which is an inhibitor of the cell cycle, allowing the cell to escape from cellular senescence and continue to proliferate [54]. There are other genes that have shown to be hypermethylated across different types of cancer as RASSF1A (tumour suppressor gene Ras association domain family member 1) [47, 51, 56-58] and P16INK4a (cyclin-dependent kinase inhibitor) [51, 52, 56, 59-61] and genes that are hypermethylated in specific types of cancers, such as GSTP1 that is methylated in $90 \%$ of prostate cancer but unmethylated in other types [51, 56], or $B R C A 1$ hypermethylated in breast and ovarian cancers $[47,51,56,62]$, among others.

\begin{tabular}{|l|l|l|l|l|}
\hline Gene & $\begin{array}{l}\text { Methylation } \\
\text { status in cancer }\end{array}$ & Disease & Cancer Cell Line & Reference \\
\hline P16INK4a & hypermethylated & $\begin{array}{l}\text { Variety of cancers } \\
\text { (e.g. Colon, Breast, } \\
\text { Renal, Prostate } \\
\text { and Lung cancers, } \\
\text { Leukaemia and } \\
\text { Melanoma) }\end{array}$ & $\begin{array}{l}\text { Variety of cancer cell } \\
\text { lines from Colon } \\
\text { cancer, Breast cancer, } \\
\text { Renal cancer, Prostate } \\
\text { cancer, Lung cancer } \\
\text { Leukaemia and } \\
\text { Melanoma }\end{array}$ & {$[63,64]$} \\
\hline RASSF1A & hypermethylated & $\begin{array}{l}\text { Variety of cancers } \\
\text { (e.g. Leukaemia, } \\
\text { Colon, Breast, } \\
\text { Ovarian, Lung, } \\
\text { Prostate, Renal }\end{array}$ & $\begin{array}{l}\text { Variety of cancer cell } \\
\text { lines from } \\
\text { Leukaemia, Colon } \\
\text { cancer, Breast cancer, } \\
\text { Ovarian cancer, Lung }\end{array}$ & {$[57,58$,} \\
\hline
\end{tabular}




\begin{tabular}{|c|c|c|c|c|}
\hline Gene & $\begin{array}{l}\text { Methylation } \\
\text { status in cancer }\end{array}$ & Disease & Cancer Cell Line & Reference \\
\hline & & $\begin{array}{l}\text { and CNS (central } \\
\text { nervous system) } \\
\text { cancers and } \\
\text { Melanoma) }\end{array}$ & $\begin{array}{l}\text { cancer, Prostate } \\
\text { cancer, Renal cancer, } \\
\text { CNS cancer and } \\
\text { Melanoma. }\end{array}$ & \\
\hline P15INK4a & hypermethylated & $\begin{array}{l}\text { Leukaemia, Lung } \\
\text { and Breast cancers }\end{array}$ & $\begin{array}{l}\text { Cancer cell lines from } \\
\text { Leukaemia, Lung } \\
\text { cancer and Breast } \\
\text { cancer }\end{array}$ & {$[63,64]$} \\
\hline P14ARF & hypermethylated & $\begin{array}{l}\text { Colon, Breast and } \\
\text { Renal cancers and } \\
\text { Leukaemia }\end{array}$ & $\begin{array}{l}\text { Cancer cell lines from } \\
\text { Colon cancer, Breast } \\
\text { cancer, Renal cancer } \\
\text { and Leukaemia }\end{array}$ & {$[63,64]$} \\
\hline MLH1 & hypermethylated & Colon cancer & Colon cancer cell lines & {$[63,64]$} \\
\hline BRCA1 & hypermethylated & Breast cancer & $\begin{array}{l}\text { Breast cancer cell } \\
\text { lines }\end{array}$ & [65] \\
\hline MGMT & hypermethylated & $\begin{array}{l}\text { Leukaemia, } \\
\text { Colon, Renal, } \\
\text { Breast and Lung } \\
\text { cancers and } \\
\text { Melanoma, CNS } \\
\text { cancer }\end{array}$ & $\begin{array}{l}\text { Cancer cell lines from } \\
\text { Leukaemia, Colon } \\
\text { cancer, Renal cancer, } \\
\text { Breast cancer, Lung } \\
\text { cancer, Melanoma } \\
\text { and CNS cancer }\end{array}$ & {$[63,64]$} \\
\hline DAPK & hypermethylated & $\begin{array}{l}\text { Leukaemia, Lung, } \\
\text { Colon, CNS, } \\
\text { Prostate and } \\
\text { Breast cancer and } \\
\text { Melanoma }\end{array}$ & $\begin{array}{l}\text { Cancer cell lines from } \\
\text { Leukemia, Lung } \\
\text { cancer, Colon cancer, } \\
\text { CNS cancer, Prostate } \\
\text { cancer, Breast cancer } \\
\text { and Melanoma }\end{array}$ & {$[63,64]$} \\
\hline GSTP1 & hypermethylated & $\begin{array}{l}\text { Prostate, Breast } \\
\text { and Lung cancers }\end{array}$ & $\begin{array}{l}\text { Cancer cell lines from } \\
\text { Prostate cancer, } \\
\text { Breast cancer and } \\
\text { Lung cancer }\end{array}$ & {$[64,66]$} \\
\hline NM23-H1 & hypermethylated & MPNST & $\begin{array}{l}\text { MPNST cancer cell } \\
\text { lines }\end{array}$ & [15] \\
\hline DSC3 & hypermethylated & Breast cancer & $\begin{array}{l}\text { Breast cancer cell } \\
\text { lines }\end{array}$ & [67] \\
\hline MASPIN & hypermethylated & Breast cancer & $\begin{array}{l}\text { Breast cancer cell } \\
\text { lines }\end{array}$ & [67] \\
\hline$c-M Y C$ & hypomethylated & $\begin{array}{l}\text { Gastric and Colon } \\
\text { cancer }\end{array}$ & $\begin{array}{l}\text { Gastric and Colon } \\
\text { cancer cell lines }\end{array}$ & [68] \\
\hline
\end{tabular}

Table 3. Examples of genes displaying an alterated methylation status in cancer cell lines. 
The information available about hypermethylation in cancer is much higher than the one concerning hypomethylation [51]. However, both conditions may lead to loss of cell cycle control and apoptosis signals, change in the function of transcription factors, genomic instability, among many other effects [55]. Unlike the hypermethylation, the global hypomethylation in cancer occurs more frequently in highly and moderately repeated DNA sequences but can also be seen in single-copy sequences [49]. These single copy-sequences can be oncogenes, like $c-M Y C[49,51,54]$ (table 3), and these can be also associated with tumour initiation and/or progression [49]. But generally, the global genome hypomethylation promotes cancer progression by the induction of chromosome instability [51, 54, 56], loss of imprinting [54, 56] and reactivation of transposable elements [51, 54]. Thus, the aberrant hypomethylation pattern, which occurs early in tumorigenesis, can be also used as a biomarker [49], highlighting the importance of its analysis in cancer cells.

Unlike the genetic, the methylation modifications are reversible $[3,50]$, making this event excellent for analysis in cancer cell lines and a promising target for therapy. The study of DNA methylation in cancer cell lines has been accomplished using demethylating agents, such as 5-Azacytidine (5-AZA) and its deoxy derivative 5-Aza-2'deoxycytidine (decitabine), that cause global genome demethylation $[1,5,19,51,67]$. These demethylating agents are used in epigenetic therapy, restoring the hypomethylation state by the inversion of the gene silencing induced by hypermethylation $[1,51]$. These drugs are based in a cytosine analogue that are incorporated in the DNA (decitabine) after phosphorylation or in both the DNA and RNA (5-AZA), inhibiting DNMTs (DNA methyltransferases) to methylate the DNA, leading to a decrease of the DNA methylation level [51,53]. Although the numerous studies on these demethylating agents, their exact mechanism of action and effects in tumour cells remains arguable $[1,52,69,70]$.

These drugs, used as chemotherapeutic agents in certain types of cancers [50, 52-54, 69], are also used to screen for changes in gene expression thought to be regulated by methylation in cell lines $[1,5,15,53,54,56]$. These demethylating agents that act as DNMTs inhibitors have shown the ability to reactivate epigenetically silenced tumour suppressor genes in cancer cell lines. Thus, these drugs can also be used as molecular research tools for the induction of DNA demethylation in cancer cell lines [53, 69]. In fact, they have been used in many research works for the analysis of the methylation profile before and after cells treatment, allowing the identification of epigenetically altered genes [1, 15, 53]. For instance, the transcriptional profile of cancer cell lines of esophageal squamous cell carcinoma (ESCC) treated with 5-azacytidine allowed the identification of various putative tumour suppressor genes that are hypermethylated in these cells [53]. Fang and colleagues (2009) proved that the loss of expression of NM23-H1, which is related with metastatic progression, in cell lines from MPNST, can be associated with the methylation of $\mathrm{CpG}$ islands in the promoter region of this gene, making this a reversible process by the use of demethylation agents as anticancer drugs [15]. Another study of demethylation in breast cancer cell lines verified the transcriptional reactivation of desmocollin 3 (DSC3) and MASPIN, that are tumour suppressor genes frequently silenced in breast cancer [67]. Louzada and colleagues (2012), alternatively, analysed the effect of decitabine in the expression of two genes in rat breast 
cancer cell lines and their results showed a decrease of Erbb2 expression (initially overexpressed in these cells), showing that this gene is epigenetically regulated [1]. Although these demethylation agents are excellent tools for the methylome profiling of cancer cell lines, another kind of methylation studies have been done using antisense RNA $[35,54]$ and interference RNA for depleting DNMTs [20, 67].

The DNA methylation profiling is difficult to perform in the majority of models, but it is extremely simple to perform in cancer cell lines, enhancing their value as cell models for the study of the methylome and to understand the relationship between the genetic and the epigenetic profiles with the effectiveness of anticancer drugs. The use of cancer cell lines as models for the methylome analysis was highlighted in a work comparing the transcriptional profiling after the treatment with decitabine in in vitro and in vivo revealing similar results, what validates the use of this model [53]. Other methylome studies performed in cancer cell lines in an epigenome-wide way were performed through the use of recent technologies as NGS. In 2010, Ruike and colleagues made a methylation profiling in breast cancer cell lines using MeDIP-seq that revealed important insights about the aberrant patterns of DNA methylation in these cell lines, allowing a more extensive study about the methylome during carcinogenesis and the correlation between the morphological changes and the observed methylome alterations [48]. These recent technologies allow the study of the methylome in cancer in an unprecedented way [47], but this type of studies are still in the beginning [47].

The methylome profiling is essential for the early cancer detection, prognostic and treatment $[50,51,55]$, for the development of new epigenetic therapies [54], for distinguishing tumour types and subtypes using molecular biomarkers and predict the chemotherapy response [51, 54, 55]. But the use of cancer cell lines for the study of DNA methylation alterations in cancer is controversial. Although some authors consider it a good model, that have shown similar results in the methylome profile when comparing the results in vivo and in vitro [53]; there are others, instead, believing that this type of studies should be made in non-cultured cells due to the in vitro culture environment $[49,50]$. Nevertheless, the problems in the association of the epigenetic profiles with cancer, when using other models (difficulties in manipulation, sample selection, sample size, data integration, among others [50]), can be, in part, solved with the use of cancer cell lines. Thus, it is crucial to analyse the relationship between methylation in cancer and the resistance/sensitivity to anticancer drugs in wellcharacterized cancer cell lines, making possible the detection of potential drug targets and drug resistance markers [47].

\section{Drug testing in cancer cell lines}

Drug testing in cancer cell lines is usually one of the initial steps in drug development. It allows the access of a large number of potential drugs before committing to large scale expensive in vivo clinical trials.

The use of cancer cell lines for cytotoxicity evaluation has been made by many researchers for many years, having clinical predictive value $[2,18]$, consistent with the expected from the original tumour. Different cancer cell lines display diverse responses to cytotoxic 
anticancer drugs, as colon cancer cell lines are more resistant to DNA intercalating-drugs and breast cancer or leukaemia cell lines are more sensitive [18]. Copeland and colleagues (2007) tested the cytotoxicity of an anticancer drug in different prostate cancer cell lines derived from prostate cancer subtypes, and confirmed that this drug is more efficient for prostate androgen-independent cancer. In this study they proposed this chemotherapeutic drug for the treatment of metastatic prostate cancer [71], that should, however, be more studied in cancer cell lines for the determination of the action mechanism.

The testing of anticancer drugs using cancer cell lines over other models presents other advantages than just cytotoxicity evaluation tests, because it permits to analyse the action of drugs, combinations of them and the screening for resistance/sensitivity [72], with the concomitant discovery of specific markers [10]. The identification of epigenetic or genetic alterations in specific sequences allows to specifically target the drug in order to achieve a therapeutic outcome and identify new potential druggable targets.

The fact that cancer cells have the oncogenic pathway activated makes these cells less dependent of extracellular regulators. Cancer cell lines also have this pathway activated [3], retaining the genomic deregulation of transcription of the primary tumour [24], but, at the same time, also have a more simple transcriptome by the loss of unneeded functions [3], making this one of the best models for anticancer drug testing (single drugs or in combination) $[2,3,6,10,18,24,71]$. This is valid not only in a first approach, but also for understanding drugs' mechanisms of action [10,73], the resistance/sensitivity of some types of cancer to different drugs [10, 24, 72,74], for the discovery of biomarkers for anticancer drugs response (resistance/sensitivity markers) [10,75,76], or for the research of signalling pathways associated with the therapeutic response [2, 24], among others. Nevertheless, even if a cancer cell line comes from the same subtype of tumour, it must be well-characterized before its use in anticancer drug testing due to the fact that similar cell lines may present different signatures from each other, although retaining the same signature of the original tumour $[3,24]$. An example are cancer cell lines derived from the same subtype of tumour as thyroid papillary carcinomas B-CPAP and TPC-1, displaying different oncogenic pathways modified, maintaining that from the original tumour [3]. Others than cancer cell line models, will always be needed for the validation of the data, being the clinical trials mandatory before the use of any drug in a clinical approach.

The use of cell line panels is a useful tool for anticancer drug testing. The development of these cancer cell lines panels was initiated for the panel NCI60 (panel US National Cancer Institute with 60 cancer cell lines) in order to overcome the use of animal models for the test of antineoplastic drugs [12]. Afterwards, Nakatsu and colleagues (2005) established a panel of 45 cancer cell lines (JFCR-45) from different origins (breast, liver and stomach) to determine genes related with chemosensitivity to anticancer drugs. They also tried to understand the mechanisms of action of these drugs for their classification. This research, that involved an integrated bioinformatic approach using cDNA arrays, revealed many candidate genes associated with sensitivity to chemotherapeutic drugs. For the correct identification of these genes, they transfected each one in the different cell lines and discover 
that the overexpression of HSPA1A and JUN genes increased the sensitivity to mitomycin C, suggesting that these genes play a role in the response to this anticancer drug. The genes discovered in this study can be used as predictive markers of sensitivity to chemotherapeutic drugs, which is crucial for a higher effectiveness of the treatment [10]. Recently, Garnett and colleagues (2012) screened a panel of several hundred cancer cell lines (representing much of the tissue-type and genetic diversity of human cancers) with 130 drugs under clinical and preclinical investigation and verified that the cancer genes mutated are related with the cellular response to the most commonly used drugs, making this systematic pharmacogenomic profiling in cancer cell lines a powerful biomarker discovery platform to guide rational cancer therapeutic strategies [75]. The use of a cell line panel with subtypes of cancer cell lines for studying the signalling pathways involved in the therapeutic response was made by Neve and colleagues (2006) that used Herceptin ${ }^{\circledR}$ (Trastuzumab) immunotherapy in a system of cancer cell lines ERBB2+, that do not respond to this therapy, to identify the molecular signature associated with this phenotype [24]. Thus, the use of cancer cell line panels seems to be a powerful system for underlying the molecular mechanisms of anticancer drug response [2].

The existence of databases with detailed genetic and pharmacologic information from cancer cell lines allows the generation of genetic predictions of drug response in the preclinical setting. An example is Cancer Cell Line Encyclopedia (CCLE, launched by Novartis), a database that contains genes' expression profiling, massively parallel sequencing and chromosomal copy number data from almost a thousand human cancer cell lines. The integration of the pharmacologic profiles of anticancer drugs with the data from the cell lines deposited in CCLE allowed Barrentina and colleagues (2012) to identify genetic, lineage, and gene-expression-based predictors of drug sensitivity [76]. However, the problem of working with cancer cell lines characterized too many years ago or not characterized at all, will definitely difficult data interpretation or even lead to misinterpretations.

The availability of molecular modelling tools, such as QSAR (Quantitative Structure Activity Relationships), giving insights about the molecular interactions of the compounds studied with proteins involved in signalling pathways [77], or docking methods that predict the strength of association or binding affinity between a drug to a particular target [78], are also fundamental tools that should be considered in drug testing studies.

The characterization of cancer cell lines about the state of cell cycle checkpoints [15, 28], regulatory cell cycle proteins [28] and the presence of Multidrug Resistance Domains (MDR) [72], are also essential in anticancer drug testing. The effect of anticancer drugs in cancer cell lines must be screened on cell cycle progression, checkpoint signalling pathways and cell proliferation, making important the characterization of these parameters in cancer cell lines before their use as models. For instance, the characterization of several cell lines from head and neck squamous cell carcinoma (HNSCC) allowed to disclose that most of them lack the checkpoint function by loss of P53 and RB functions and their upstream and downstream regulation pathways (e.g. MDM2 and CDK6, respectively) [28]. Cell cycle profiling 
(progression and checkpoints regulators) of cancer cell lines is thus a valuable tool in the development of chemotherapeutic agents as therapeutic targets [28, 79]. In the case of antimitotic drugs, the analysis of Microtubules (MTs) and centrosomal proteins [72] should also be considered.

One of the more successful anticancer drug targets are microtubules. These form a highly dynamic structure constituted by polymers of $\alpha$ and $\beta$-tubulin essential for the development and maintenance of cellular morphology, protein trafficking in the cell, cell signalling and proper chromosome segregation during mitosis $[72,80]$. Their importance in mitosis by their mitotic spindle assembly and dynamics required for proper chromosome segregation make the microtubules an excellent target for antimitotic therapy [72]. At the moment, three different groups of MT-targeted anticancer drugs are widely used for chemotherapy: Vinca alkaloids (e.g. vinblastine) [72, 73], taxanes (e.g. paclitaxel - Taxol $^{\circledR}$ ) [10, 28, 72] and colchicine [72]. These antimitotic drugs bind to different binding sites in $\beta$-tubulin, exhibit different behaviours and are used for different types of cancer. These drugs act by suppression of the MT dynamics, leading to mitotic blocking and cell death by apoptosis [72]. However, the exact mechanism of action of these drugs, the resistance/sensitivity mechanisms and the combination of these drugs with others is an incomplete research field, and cancer cell lines can be excellent models for the study of these drugs as long as they are well-characterized.

Coleman and colleagues (2002) used cancer cell lines from HNSCC for determination of the mechanism of action of two drugs combination, paclitaxel and carboplatin. They concluded that the paclitaxel activity is related with the increase of cyclin B1/CDC2 activity, BCL-2 phosphorylation and mitotic block, affecting the cells in mitosis. However, their study proved that the efficiency in the inhibition of cell proliferation was higher when combining these two drugs, allowing the use of this combination in other models [28]. In other work, the sensitivity of tumour cells to paclitaxel in the absence of PLK1 (polo-like kinase 1) was studied in breast cancer cell lines [81]. PLK1 play a key role in different stages of mitosis and its overexpression is a negative prognostic indicator [81, 82]. The use of antisense oligonucleotides for PLK1 depletion leaded to the conclusion that the presence of these antisense oligos increase the response to paclitaxel [81]. Huang and colleagues (2004) studied the apoptosis induction of Vinca alkaloids in cancer cell lines. The type of analysis performed by these authors, as the use of glucocorticoids to inhibit mitotic arrest caused by Vinca alkaloids or transfection with antisense oligonucleotides are difficult to perform in other types of models. Moreover, this study revealed another signalling pathway $(\mathrm{NF}-\kappa \mathrm{B} / \mathrm{I} \kappa \mathrm{B})$ that might be related with apoptosis induction by this antimitotic drug [73].

As referred, drug resistance is a major problem in cancer chemotherapy [80, 83]. The study of the mechanisms that lead to a resistant cell can involve a diversity of molecules. Although there is no complete understanding about what leads to cell resistance to certain types of drugs, some of them are already known. Multidrug Resistance is a mechanism of drug efflux that can be caused by the upregulation of MDR1 gene, leading to an increase of membrane transporters as p-glycoprotein (P-GP) $[40,72,83]$. However, it is not completely 
understood, and the apoptotic pathway also has influence in the resistance to anticancer drugs $[28,40,83]$. The resistance to paclitaxel was related with upregulation of antiapoptotic BCL-2 family members as BCL-2 e BCL-XL [40]. The resistance of tumour cells to paclitaxel and also to other antimitotic drugs can also be attributed to differences in the expression of tubulin isotypes, point mutations or post-translational modifications in $\beta$-tubulin residues that modify the binding site [40,72,80], binding of MT-regulatory proteins [72], decrease of CDK (cyclin-dependent kinase) level, which cause a mitotic delay, overexpression of the microtubule associated protein tau mRNA and decrease in affinity of targeted drugs to the target (MTs) [40]. Anticancer drug resistance can also be related with other tubulin forms or other proteins in the centrosome in interphase or mitotic spindle poles in mitosis, but it clearly exists a need for much more research in this field [72]. The use of cancer cell lines for resistance/sensitivity studies is imperative, neverless, their poor characterization can lead to problems in the data interpretation. Nakayama and colleagues (2009) used breast cancer cell lines and xenograft models for the discovery of characteristics related with the sensitivity or resistance to paclitaxel. They deduced that the in vitro response to paclitaxel do not predict exactly the sensitivity to this drug in vivo (80\%) [40]. However they used cancer cell lines like MCF7 that were established many years ago and need to be properly characterized, as already mentioned. An altered response to certain compounds can also occur by the clonal variants of cancer cell lines and the xenograft may exhibit a cellular environment that can modify the response [5]. More importantly, they concluded that the decrease of CDK1 (cyclin-dependent kinase) is related with tumour cells' resistance and that the increase of CDK2 is required for the increase of sensitivity. Thus, analysis of CDKs can predict clinically the sensitivity to paclitaxel [40]. Nakatsu and colleagues (2005) also used cancer cell lines for the identification of genes related with the sensitivity to paclitaxel (and other anticancer drugs). With their work, they found that the genes related with tubulin-binder and cytoskeleton-related as VIL2 (encoding ezrin) and ACTB (encoding h-actin) are related with the paclitaxel chemosensitivity, proposing these genes as predictor markers for anticancer drug efficacy [10]. In other work using cancer cell lines as models for paclitaxel resistance analysis, the cells were transformed into resistant by the progressive increase of the drug [80]. The profiling of cancer cell lines paclitaxel-resistants' can allow the identification of resistance mechanisms [72].

The knowledge of the specific composition of MT regulatory proteins or other regulatory proteins and different tubulin isotypes of cancer cell lines, and the way these interfere with the effectiveness of MT-targeted drugs, can be helpful for a better clinical application of these drugs and for the development of molecularly targeted drugs by its combination, overcoming the MDR $[72,83]$ and the side effects as neuropathy. For this, it is essential to understand the exact mechanism of action of antimitotic drugs, the relation of drug-induced mitotic block and cell death and the interaction of these drugs with centrosomes and the mitotic spindle pole (where other types of tubulin exist). Another question is why some antimitotic drugs as taxanes are efficient in some tumours as breast, ovarian and lung, but are inefficient in kidney, colon cancers, sarcomas and others of the same group of MTtargeted drugs, like Vinca alkaloids are more efficient in hematologic malignancies and ineffective against solid tumours [72]. 
The use of different types of well-characterized cancer cell lines at the genome and methylome levels can allow the study of the mechanisms of antimitotic drugs and if the mechanism of resistance are related with the methylation pattern. Thus, the characterization of cancer cell lines at the DNA methylation level and the combination of these antimitotic drugs with 5'AZA may be a straightforward strategy to understand the mechanism of action of such drugs and testing their combination.

The profiling of cancer cell lines at the DNA methylation level is also important for the prediction of chemotherapeutic response [51]. Hypermethylation of the promoter regions of some genes, as of the DNA repair gene MGMT that happens in glioma, increases the sensitivity to alkylating agents as carmustine $\left(\mathrm{BiCNU}^{\circledR}\right)$ [51, 54]. Arnold and colleagues (2003) analysed hypermethylated colorectal cancer cell lines after exposure to a demethylating drug and found that the hypermethylation of the gene MLH1 was reverted by these type of drugs, decreasing the resistance to the anticancer drug fluorouracil (5-FU) [84]. Shen and colleagues (2007) in a work performed in the NCI60 panel of cancer cell lines were able to elaborate a list of methylation markers to predict the anticancer drug response [63]. These works highlight the fact that methylation/demethylation studies performed in cell lines definitely provide a powerful system model for the definition of new candidate strategies to overcome the problem of drug resistance in the treatment of cancer. The exact mechanism of action of demethylating agents or the patterns of resistance and sensitivity are unclear and it is extremely important to understand the molecular changes induced by these drugs to increase their effectiveness $[69,85]$.

As already mentioned, in cell lines, demethylating drugs, as azacytidine and decitabine cause global demethylation of DNA by the inhibition of DNMTs, reverting the gene silencing induced by hypermethylation [51-53,69]. The use of such demethylating drugs can cause inhibition of cell proliferation and G2 arrest [85] but can also lead to the reestablishment of proliferation control and apoptotic sensitivity [69]. In spite of the oversight of information about the azanucleosides, these anticancer drugs are currently used in the treatment of myelodysplastic syndrome (MDS) and other types of leukaemia [51-53, 85]. However, it is essential an improved knowledge on the mechanisms of action of these epigenetic drugs at the molecular level and the cellular pathways that they influence, as well as the identification and validation of response predictor markers [69] for the application of these drugs in more cancer types and with conjugation with other anticancer drugs.

The development of treatments that accomplish a specific reversion of DNA methylation modifications without interfering in the normal epigenetic events required for the cellular function [53] has stimulated the research of other inhibitors of DNMTs [51, 53]. The use of cancer cell lines allows the testing of other potential demethylating agents with the purpose to observe the effect of such drugs in tumour cells. Other demethylating agents as hydralazine and procainamide (cardiovascular drugs) in breast cancer cell lines cause demethylation and expression reestablishment of $E R, R A R \beta$, and P16INK4a [86]. Alternative inhibitors of DNMTs that have focused the researchers attention are DNMT antisense and siRNA [51, 53]. It was proved in colon and bladder cancer cell lines that an antisense oligodeoxynucleotide as MG98 is a DNMT1 antisense inhibitor that cleaves its mRNA 
resulting in the demethylation and replacement of the normal expression of P16INK4a [87]. The siRNA can be designed as an inhibitor of DNMTs, but can also be used as a target for the proteins involved in the regulation of the methylated gene [51].

So, the characterization of both the genome and methylome of cancer cell lines allows the discovery of targets to anticancer drugs and to create more targeted drugs for certain types of cancer, providing the development of new therapies [35], as the use of siRNA, or the combination of new or already existing ones.

The use of siRNA in cancer therapy is a new research field and promises to silence critical cancer genes, as oncogenes [88]. The use of cell lines was essential for the discovery of this potential specific gene cancer therapy by the suppression of expression of these genes [89] and blocking of the biological processes that comprise the hallmarks of cancer [88]. The major problem of using siRNAs as anticancer therapeutics does not rely in their design or mechanism of action, but in their delivery. To overcome this problem, nanoparticles $[88,90]$ (lipid, organic or inorganic) have been used for degradation protection, facilitating the cell transfection and allowing the delivery in the right place [88]. Presently, some siRNAs that use nanoparticles as delivery vehicles are in clinical trials $[88,90]$, however, at the moment, none have been approved [88]. A siRNA against PLK1 is in conclusion of phase I of clinical trials in different types of cancer [88] (http://www.clinicaltrials.gov/ct2/show/ record/NCT01437007) and good results are expected because of the importance of this protein in mitosis and in the maintenance of genome stability [82]. Another siRNA that is in a clinical trial phase with successful results is a siRNA for the depletion of M2 subunit of Ribonuclease reductase (RRM2) in solid tumours [88, 90, 91] (http://www.clinicaltrials.gov/ct2/show/NCT00689065), decreasing the proliferation of cancer cells in vitro and in vivo [91]. The mutation of K-RAS is associated with one third of the human cancers and is a resistance factor of many cancers to therapy. The depletion of this protein is an excellent target for cancer treatment, leading cancer cells to apoptosis. A phase I of a clinical trial is being carried out for this target (siG12D LODER (Local Drug EluteR)) in patients with pancreas adenocarcinoma, since most of the pancreas cancer cells have K-RAS mutated [88] (http://www.clinicaltrials.gov/ct2/show/NCT01188785). Although none siRNAs are yet available for cancer treatment, it is expected that in the near future they could be used as cancer therapeutic agents.

The identification of more cancer-type related genes, DNA methylation profiles and altered cellular pathways in cancer cell lines is crucial for understanding drugs' mechanisms of action and its resistance patterns, and for developing and testing new targeted anticancer drugs.

\section{Conclusion}

In conclusion, well-characterized cancer cell lines at the molecular level are excellent models for the study of the altered cellular pathways, critical genes and methylome in cancer, and for anticancer drug testing. Although we have now a reasonable knowledge of the genome of this model, we are still in the beginning of knowing its methylome. The recent 
technologies are very useful for this molecular profiling, which is absolutely required before the use of any cancer cell line in a research program. The study of the methylome in cancer using cell models is essential, since epigenetic modifications can occur early in oncogenesis, being the DNA methylation pattern a good target for chemotherapy. The molecular cancer cell lines profiling is also essential for the development of new anticancer drugs and for understanding the mechanism of action and the patterns involved in cell resistance to chemotherapeutics already used in the treatment of cancer. Moreover, cancer cell lines profiling can be a powerful tool for the identification of genes' alterations or pathways cancer-related and for the discovery of putative drug targets.

\section{Nomenclature}

In the present work the nomenclature for human genes and proteins was the one recommended by HGNC (HUGO Gene Nomenclature Committee). For mouse and rat, we followed the one suggested by MGI (Mouse Genome Informatics).

\section{Author details}

Daniela Ferreira, Filomena Adega and Raquel Chaves*

Institute for Biotechnology and Bioengineering, Centre of Genomics and Biotechnology,

University of Trás-os-Montes and Alto Douro (IBB/CGB-UTAD), Quinta de Prados,

Vila Real, Portugal

\section{Acknowledgement}

This work was supported by a research position on Animal Genomics of the "Sistema Científico e Tecnológico Nacional - Ciência 2007" and a PhD grant SFRH/BD/80446/2011, from the Science and Technology Foundation (FCT) from Portugal.

\section{References}

[1] Louzada S, Adega F, Chaves R. Defining the sister rat mammary tumor cell lines HH-16 cl.2/1 and HH-16.cl.4 as an in vitro cell model for Erbb2. PloS one 2012;7(1) e29923.

[2] Vargo-Gogola T, Rosen JM. Modelling breast cancer: one size does not fit all. Nature reviews Cancer 2007;7(9) 659-672.

[3] van Staveren WC, Solis DY, Hebrant A, Detours V, Dumont JE, Maenhaut C. Human cancer cell lines: Experimental models for cancer cells in situ? For cancer stem cells? Biochimica et biophysica acta 2009;1795(2) 92-103.

[4] Burdall SE, Hanby AM, Lansdown MR, Speirs V. Breast cancer cell lines: friend or foe? Breast cancer research : BCR 2003;5(2) 89-95.

\footnotetext{
${ }^{*}$ Corresponding Author
} 
[5] Lacroix M, Leclercq G. Relevance of breast cancer cell lines as models for breast tumours: an update. Breast cancer research and treatment 2004;83(3) 249-289.

[6] Leonetti C, Scarsella M, Zupi G, Zoli W, Amadori D, Medri L, Fabbri F, Rosetti M, Ulivi $\mathrm{P}$, Cecconetto $\mathrm{L}$ et al. Efficacy of a nitric oxide-releasing nonsteroidal anti-inflammatory drug and cytotoxic drugs in human colon cancer cell lines in vitro and xenografts. Molecular cancer therapeutics 2006;5(4) 919-926.

[7] Engel LW, Young NA, Tralka TS, Lippman ME, O'Brien SJ, Joyce MJ. Establishment and characterization of three new continuous cell lines derived from human breast carcinomas. Cancer research 1978;38(10) 3352-3364.

[8] Gazdar AF, Girard L, Lockwood WW, Lam WL, Minna JD. Lung cancer cell lines as tools for biomedical discovery and research. Journal of the National Cancer Institute 2010;102(17) 1310-1321.

[9] Ruhe JE, Streit S, Hart S, Wong CH, Specht K, Knyazev P, Knyazeva T, Tay LS, Loo HL, Foo $\mathrm{P}$ et al. Genetic alterations in the tyrosine kinase transcriptome of human cancer cell lines. Cancer research 2007;67(23) 11368-11376.

[10] Nakatsu N, Yoshida Y, Yamazaki K, Nakamura T, Dan S, Fukui Y, Yamori T. Chemosensitivity profile of cancer cell lines and identification of genes determining chemosensitivity by an integrated bioinformatical approach using cDNA arrays. Molecular cancer therapeutics 2005;4(3) 399-412.

[11] Pfragner R, Behmel A, Hoger H, Beham A, Ingolic E, Stelzer I, Svejda B, Moser VA, Obenauf AC, Siegl V et al. Establishment and characterization of three novel cell lines P-STS, L-STS, H-STS - derived from a human metastatic midgut carcinoid. Anticancer research 2009;29(6) 1951-1961.

[12] Shoemaker RH. The NCI60 human tumour cell line anticancer drug screen. Nature reviews Cancer 2006;6(10) 813-823.

[13] Kao J, Salari K, Bocanegra M, Choi YL, Girard L, Gandhi J, Kwei KA, HernandezBoussard T, Wang P, Gazdar AF et al. Molecular profiling of breast cancer cell lines defines relevant tumor models and provides a resource for cancer gene discovery. PloS one $2009 ; 4(7)$ e6146.

[14] Wistuba, II, Behrens C, Milchgrub S, Syed S, Ahmadian M, Virmani AK, Kurvari V, Cunningham TH, Ashfaq R, Minna JD et al. Comparison of features of human breast cancer cell lines and their corresponding tumors. Clinical cancer research : an official journal of the American Association for Cancer Research 1998;4(12) 2931-2938.

[15] Fang Y, Elahi A, Denley RC, Rao PH, Brennan MF, Jhanwar SC. Molecular characterization of permanent cell lines from primary, metastatic and recurrent malignant peripheral nerve sheath tumors (MPNST) with underlying neurofibromatosis-1. Anticancer research 2009;29(4) 1255-1262.

[16] Hakozaki M, Hojo H, Sato M, Tajino T, Yamada H, Kikuchi S, Abe M. Establishment and characterization of a new cell line, FPS-1, derived from human undifferentiated pleomorphic sarcoma, overexpressing epidermal growth factor receptor and cyclooxygenase-2. Anticancer research 2006;26(5A) 3393-3401.

[17] Tomlinson GE, Chen TT, Stastny VA, Virmani AK, Spillman MA, Tonk V, Blum JL, Schneider NR, Wistuba, II, Shay JW et al. Characterization of a breast cancer cell line 
derived from a germ-line BRCA1 mutation carrier. Cancer research 1998;58(15) 32373242.

[18] Finlay GJ, Baguley BC. The use of human cancer cell lines as a primary screening system for antineoplastic compounds. European journal of cancer \& clinical oncology 1984;20(7) 947-954.

[19] Leone G, Voso MT, Teofili L, Lubbert M. Inhibitors of DNA methylation in the treatment of hematological malignancies and MDS. Clin Immunol 2003;109(1) 89-102.

[20] Kawasaki H, Taira K. Induction of DNA methylation and gene silencing by short interfering RNAs in human cells. Nature 2004;431(7005) 211-217.

[21] Anglard P, Trahan E, Liu S, Latif F, Merino MJ, Lerman MI, Zbar B, Linehan WM. Molecular and cellular characterization of human renal cell carcinoma cell lines. Cancer research 1992;52(2) 348-356.

[22] Bright RK, Vocke CD, Emmert-Buck MR, Duray PH, Solomon D, Fetsch P, Rhim JS, Linehan WM, Topalian SL. Generation and genetic characterization of immortal human prostate epithelial cell lines derived from primary cancer specimens. Cancer research 1997;57(5) 995-1002.

[23] Trojan L, Schaaf A, Steidler A, Haak M, Thalmann G, Knoll T, Gretz N, Alken P, Michel MS. Identification of metastasis-associated genes in prostate cancer by genetic profiling of human prostate cancer cell lines. Anticancer research 2005;25(1A) 183-191.

[24] Neve RM, Chin K, Fridlyand J, Yeh J, Baehner FL, Fevr T, Clark L, Bayani N, Coppe JP, Tong $\mathrm{F}$ et al. A collection of breast cancer cell lines for the study of functionally distinct cancer subtypes. Cancer cell 2006;10(6) 515-527.

[25] Li SJ, Ren GX, Jin WL, Guo W. Establishment and characterization of a rabbit oral squamous cell carcinoma cell line as a model for in vivo studies. Oral oncology 2011;47(1) 39-44.

[26] Hughes L, Malone C, Chumsri S, Burger AM, McDonnell S. Characterisation of breast cancer cell lines and establishment of a novel isogenic subclone to study migration, invasion and tumourigenicity. Clinical \& experimental metastasis 2008;25(5) 549-557.

[27] Djojosubroto M, Bollotte F, Wirapati P, Radtke F, Stamenkovic I, Arsenijevic Y. Chromosomal number aberrations and transformation in adult mouse retinal stem cells in vitro. Investigative ophthalmology \& visual science 2009;50(12) 5975-5987.

[28] Coleman SC, Stewart ZA, Day TA, Netterville JL, Burkey BB, Pietenpol JA. Analysis of cell-cycle checkpoint pathways in head and neck cancer cell lines: implications for therapeutic strategies. Archives of otolaryngology--head \& neck surgery 2002;128(2) 167-176.

[29] Albini A, Benelli R, Noonan DM, Brigati C. The "chemoinvasion assay": a tool to study tumor and endothelial cell invasion of basement membranes. The International journal of developmental biology 2004;48(5-6) 563-571.

[30] Ikediobi ON, Davies H, Bignell G, Edkins S, Stevens C, O'Meara S, Santarius T, Avis T, Barthorpe S, Brackenbury L et al. Mutation analysis of 24 known cancer genes in the NCI-60 cell line set. Molecular cancer therapeutics 2006;5(11) 2606-2612. 
[31] Osborne CK, Hobbs K, Trent JM. Biological differences among MCF-7 human breast cancer cell lines from different laboratories. Breast cancer research and treatment 1987;9(2) 111-121.

[32] MacLeod RA, Dirks WG, Matsuo Y, Kaufmann M, Milch H, Drexler HG. Widespread intraspecies cross-contamination of human tumor cell lines arising at source. International journal of cancer Journal international du cancer 1999;83(4) 555-563.

[33] Dangles-Marie V, Pocard M, Richon S, Weiswald LB, Assayag F, Saulnier P, Judde JG, Janneau JL, Auger N, Validire P et al. Establishment of human colon cancer cell lines from fresh tumors versus xenografts: comparison of success rate and cell line features. Cancer research 2007;67(1) 398-407.

[34] Forozan F, Mahlamaki EH, Monni O, Chen Y, Veldman R, Jiang Y, Gooden GC, Ethier SP, Kallioniemi A, Kallioniemi OP. Comparative genomic hybridization analysis of 38 breast cancer cell lines: a basis for interpreting complementary DNA microarray data. Cancer research 2000;60(16) 4519-4525.

[35] Bieche I, Onody P, Laurendeau I, Olivi M, Vidaud D, Lidereau R, Vidaud M. Real-time reverse transcription-PCR assay for future management of ERBB2-based clinical applications. Clinical chemistry 1999;45(8 Pt 1) 1148-1156.

[36] Elstrodt F, Hollestelle A, Nagel JH, Gorin M, Wasielewski M, van den Ouweland A, Merajver SD, Ethier SP, Schutte M. BRCA1 mutation analysis of 41 human breast cancer cell lines reveals three new deleterious mutants. Cancer research 2006;66(1) 41-45.

[37] Urban AE, Korbel JO, Selzer R, Richmond T, Hacker A, Popescu GV, Cubells JF, Green R, Emanuel BS, Gerstein MB et al. High-resolution mapping of DNA copy alterations in human chromosome 22 using high-density tiling oligonucleotide arrays. Proceedings of the National Academy of Sciences of the United States of America 2006;103(12) 45344539 .

[38] de Cremoux P, Tran-Perennou C, Brockdorff BL, Boudou E, Brunner N, Magdelenat H, Lykkesfeldt AE. Validation of real-time RT-PCR for analysis of human breast cancer cell lines resistant or sensitive to treatment with antiestrogens. Endocrine-related cancer 2003;10(3) 409-418.

[39] Kadota M, Yang HH, Gomez B, Sato M, Clifford RJ, Meerzaman D, Dunn BK, Wakefield LM, Lee MP. Delineating genetic alterations for tumor progression in the MCF10A series of breast cancer cell lines. PloS one 2010;5(2) e9201.

[40] Nakayama S, Torikoshi Y, Takahashi T, Yoshida T, Sudo T, Matsushima T, Kawasaki Y, Katayama A, Gohda K, Hortobagyi GN et al. Prediction of paclitaxel sensitivity by CDK1 and CDK2 activity in human breast cancer cells. Breast cancer research : BCR 2009;11(1) R12.

[41] Rhodes A, Borthwick D, Sykes R, Al-Sam S, Paradiso A. The use of cell line standards to reduce HER-2/neu assay variation in multiple European cancer centers and the potential of automated image analysis to provide for more accurate cut points for predicting clinical response to trastuzumab. American journal of clinical pathology 2004;122(1) 51-60.

[42] Hurd PJ, Nelson CJ. Advantages of next-generation sequencing versus the microarray in epigenetic research. Briefings in functional genomics \& proteomics 2009;8(3) 174-183. 
[43] Ku CS, Naidoo N, Wu M, Soong R. Studying the epigenome using next generation sequencing. Journal of medical genetics 2011;48(11) 721-730.

[44] Goya R, Sun MG, Morin RD, Leung G, Ha G, Wiegand KC, Senz J, Crisan A, Marra MA, Hirst $\mathrm{M}$ et al. SNVMix: predicting single nucleotide variants from next-generation sequencing of tumors. Bioinformatics 2010;26(6) 730-736.

[45] Ross JS, Cronin M. Whole cancer genome sequencing by next-generation methods. American journal of clinical pathology 2011;136(4) 527-539.

[46] Hirst M, Marra MA. Next generation sequencing based approaches to epigenomics. Briefings in functional genomics 2010;9(5-6) 455-465.

[47] Huang Y, Nayak S, Jankowitz R, Davidson NE, Oesterreich S. Epigenetics in breast cancer: what's new? Breast cancer research : BCR 2011;13(6) 225.

[48] Ruike Y, Imanaka Y, Sato F, Shimizu K, Tsujimoto G. Genome-wide analysis of aberrant methylation in human breast cancer cells using methyl-DNA immunoprecipitation combined with high-throughput sequencing. BMC genomics 2010;11 137.

[49] Ehrlich M. DNA methylation in cancer: too much, but also too little. Oncogene 2002;21(35) 5400-5413.

[50] Verma M. Epigenome-Wide Association Studies (EWAS) in Cancer. Current genomics 2012;13(4) 308-313.

[51] Das PM, Singal R. DNA methylation and cancer. Journal of clinical oncology : official journal of the American Society of Clinical Oncology 2004;22(22) 4632-4642.

[52] Oki Y, Aoki E, Issa JP. Decitabine--bedside to bench. Critical reviews in oncology/hematology 2007;61(2) 140-152.

[53] Mund C, Brueckner B, Lyko F. Reactivation of epigenetically silenced genes by DNA methyltransferase inhibitors: basic concepts and clinical applications. Epigenetics : official journal of the DNA Methylation Society 2006;1(1) 7-13.

[54] Esteller M, Herman JG. Cancer as an epigenetic disease: DNA methylation and chromatin alterations in human tumours. The Journal of pathology 2002;196(1) 1-7.

[55] Baylin SB, Esteller M, Rountree MR, Bachman KE, Schuebel K, Herman JG. Aberrant patterns of DNA methylation, chromatin formation and gene expression in cancer. Human molecular genetics 2001;10(7) 687-692.

[56] Shames DS, Girard L, Gao B, Sato M, Lewis CM, Shivapurkar N, Jiang A, Perou CM, Kim YH, Pollack JR et al. A genome-wide screen for promoter methylation in lung cancer identifies novel methylation markers for multiple malignancies. PLoS medicine 2006;3(12) e486.

[57] Dammann R, Yang G, Pfeifer GP. Hypermethylation of the cpG island of Ras association domain family 1A (RASSF1A), a putative tumor suppressor gene from the 3 p21.3 locus, occurs in a large percentage of human breast cancers. Cancer research 2001;61(7) 3105-3109.

[58] Burbee DG, Forgacs E, Zochbauer-Muller S, Shivakumar L, Fong K, Gao B, Randle D, Kondo M, Virmani A, Bader S et al. Epigenetic inactivation of RASSF1A in lung and breast cancers and malignant phenotype suppression. Journal of the National Cancer Institute 2001;93(9) 691-699. 
[59] Woodcock DM, Linsenmeyer ME, Doherty JP, Warren WD. DNA methylation in the promoter region of the p16 (CDKN2/MTS-1/INK4A) gene in human breast tumours. British journal of cancer 1999;79(2) 251-256.

[60] Goto T, Mizukami H, Shirahata A, Sakata M, Saito M, Ishibashi K, Kigawa G, Nemoto $\mathrm{H}$, Sanada Y, Hibi K. Aberrant methylation of the p16 gene is frequently detected in advanced colorectal cancer. Anticancer research 2009;29(1) 275-277.

[61] Shaw RJ, Liloglou T, Rogers SN, Brown JS, Vaughan ED, Lowe D, Field JK, Risk JM. Promoter methylation of P16, RARbeta, E-cadherin, cyclin A1 and cytoglobin in oral cancer: quantitative evaluation using pyrosequencing. British journal of cancer 2006;94(4) 561-568.

[62] Esteller M, Silva JM, Dominguez G, Bonilla F, Matias-Guiu X, Lerma E, Bussaglia E, Prat J, Harkes IC, Repasky EA et al. Promoter hypermethylation and BRCA1 inactivation in sporadic breast and ovarian tumors. Journal of the National Cancer Institute 2000;92(7) 564-569.

[63] Shen L, Kondo Y, Ahmed S, Boumber Y, Konishi K, Guo Y, Chen X, Vilaythong JN, Issa JP. Drug sensitivity prediction by CpG island methylation profile in the NCI-60 cancer cell line panel. Cancer research 2007;67(23) 11335-11343.

[64] Paz MF, Fraga MF, Avila S, Guo M, Pollan M, Herman JG, Esteller M. A systematic profile of DNA methylation in human cancer cell lines. Cancer research 2003;63(5) 11141121.

[65] Guendel I, Carpio L, Pedati C, Schwartz A, Teal C, Kashanchi F, Kehn-Hall K. Methylation of the tumor suppressor protein, BRCA1, influences its transcriptional cofactor function. PloS one 2010;5(6) e11379.

[66] Millar DS, Ow KK, Paul CL, Russell PJ, Molloy PL, Clark SJ. Detailed methylation analysis of the glutathione S-transferase pi (GSTP1) gene in prostate cancer. Oncogene 1999;18(6) 1313-1324.

[67] Wozniak RJ, Klimecki WT, Lau SS, Feinstein Y, Futscher BW. 5-Aza-2'-deoxycytidinemediated reductions in G9A histone methyltransferase and histone H3 K9 dimethylation levels are linked to tumor suppressor gene reactivation. Oncogene 2007;26(1) 77-90.

[68] Luo J, Li YN, Wang F, Zhang WM, Geng X. S-adenosylmethionine inhibits the growth of cancer cells by reversing the hypomethylation status of c-myc and H-ras in human gastric cancer and colon cancer. International journal of biological sciences 2010;6(7) 784-795.

[69] Stresemann C, Lyko F. Modes of action of the DNA methyltransferase inhibitors azacytidine and decitabine. International journal of cancer Journal international du cancer 2008;123(1) 8-13.

[70] Kimura S, Kuramoto K, Homan J, Naruoka H, Ego T, Nogawa M, Sugahara S, Naito H. Antiproliferative and antitumor effects of azacitidine against the human myelodysplastic syndrome cell line SKM-1. Anticancer research 2012;32(3) 795-798.

[71] Copeland RL, Jr., Das JR, Bakare O, Enwerem NM, Berhe S, Hillaire K, White D, Beyene D, Kassim OO, Kanaan YM. Cytotoxicity of 2,3-dichloro-5,8-dimethoxy-1,4- 
naphthoquinone in androgen-dependent and -independent prostate cancer cell lines. Anticancer research 2007;27(3B) 1537-1546.

[72] Jordan MA, Wilson L. Microtubules as a target for anticancer drugs. Nature reviews Cancer 2004;4(4) 253-265.

[73] Huang Y, Fang Y, Wu J, Dziadyk JM, Zhu X, Sui M, Fan W. Regulation of Vinca alkaloid-induced apoptosis by NF-kappaB/IkappaB pathway in human tumor cells. Molecular cancer therapeutics 2004;3(3) 271-277.

[74] Tozawa K, Oshima T, Kobayashi T, Yamamoto N, Hayashi C, Matsumoto T, Miwa H. Oxaliplatin in treatment of the cisplatin-resistant MKN45 cell line of gastric cancer. Anticancer research 2008;28(4B) 2087-2092.

[75] Garnett MJ, Edelman EJ, Heidorn SJ, Greenman CD, Dastur A, Lau KW, Greninger P, Thompson IR, Luo X, Soares J et al. Systematic identification of genomic markers of drug sensitivity in cancer cells. Nature 2012;483(7391) 570-575.

[76] Barretina J, Caponigro G, Stransky N, Venkatesan K, Margolin AA, Kim S, Wilson CJ, Lehar J, Kryukov GV, Sonkin D et al. The Cancer Cell Line Encyclopedia enables predictive modelling of anticancer drug sensitivity. Nature 2012;483(7391) 603-607.

[77] Abreu RM, Ferreira IC, Calhelha RC, Lima RT, Vasconcelos MH, Adega F, Chaves R, Queiroz MJ. Anti-hepatocellular carcinoma activity using human HepG2 cells and hepatotoxicity of 6-substituted methyl 3-aminothieno[3,2-b]pyridine-2-carboxylate derivatives: in vitro evaluation, cell cycle analysis and QSAR studies. European journal of medicinal chemistry 2011;46(12) 5800-5806.

[78] Sinha R, Vidyarthi AS, Shankaracharya. A molecular docking study of anticancer drug paclitaxel and its analogues. Indian journal of biochemistry \& biophysics 2011;48(2) 101105.

[79] Stewart ZA, Pietenpol JA. Cell cycle checkpoints as therapeutic targets. Journal of mammary gland biology and neoplasia 1999;4(4) 389-400.

[80] Verdier-Pinard P, Wang F, Burd B, Angeletti RH, Horwitz SB, Orr GA. Direct analysis of tubulin expression in cancer cell lines by electrospray ionization mass spectrometry. Biochemistry 2003;42(41) 12019-12027.

[81] Spankuch B, Heim S, Kurunci-Csacsko E, Lindenau C, Yuan J, Kaufmann M, Strebhardt K. Down-regulation of Polo-like kinase 1 elevates drug sensitivity of breast cancer cells in vitro and in vivo. Cancer research 2006;66(11) 5836-5846.

[82] Strebhardt K, Ullrich A. Targeting polo-like kinase 1 for cancer therapy. Nature reviews Cancer 2006;6(4) 321-330.

[83] Tsuruo T, Naito M, Tomida A, Fujita N, Mashima T, Sakamoto H, Haga N. Molecular targeting therapy of cancer: drug resistance, apoptosis and survival signal. Cancer science 2003;94(1) 15-21.

[84] Arnold CN, Goel A, Boland CR. Role of hMLH1 promoter hypermethylation in drug resistance to 5 -fluorouracil in colorectal cancer cell lines. International journal of cancer Journal international du cancer 2003;106(1) 66-73.

[85] Palii SS, Van Emburgh BO, Sankpal UT, Brown KD, Robertson KD. DNA methylation inhibitor 5-Aza-2'-deoxycytidine induces reversible genome-wide DNA damage that is 
distinctly influenced by DNA methyltransferases 1 and 3B. Molecular and cellular biology 2008;28(2) 752-771.

[86] Segura-Pacheco B, Trejo-Becerril C, Perez-Cardenas E, Taja-Chayeb L, Mariscal I, Chavez A, Acuna C, Salazar AM, Lizano M, Duenas-Gonzalez A. Reactivation of tumor suppressor genes by the cardiovascular drugs hydralazine and procainamide and their potential use in cancer therapy. Clinical cancer research : an official journal of the American Association for Cancer Research 2003;9(5) 1596-1603.

[87] Goffin J, Eisenhauer E. DNA methyltransferase inhibitors-state of the art. Annals of oncology : official journal of the European Society for Medical Oncology / ESMO 2002;13(11) 1699-1716.

[88] Shen H, Sun T, Ferrari M. Nanovector delivery of siRNA for cancer therapy. Cancer gene therapy 2012;19(6) 367-373.

[89] Elbashir SM, Harborth J, Lendeckel W, Yalcin A, Weber K, Tuschl T. Duplexes of 21nucleotide RNAs mediate RNA interference in cultured mammalian cells. Nature 2001;411(6836) 494-498.

[90] Davis ME, Zuckerman JE, Choi CH, Seligson D, Tolcher A, Alabi CA, Yen Y, Heidel JD, Ribas A. Evidence of RNAi in humans from systemically administered siRNA via targeted nanoparticles. Nature 2010;464(7291) 1067-1070.

[91] Heidel JD, Liu JY, Yen Y, Zhou B, Heale BS, Rossi JJ, Bartlett DW, Davis ME. Potent siRNA inhibitors of ribonucleotide reductase subunit RRM2 reduce cell proliferation in vitro and in vivo. Clinical cancer research : an official journal of the American Association for Cancer Research 2007;13(7) 2207-2215. 